Article

\title{
Government Incentive Contracts for Microgrid Users
}

\author{
Guanyi Yu ${ }^{1,2}$, Qiang Lin ${ }^{3, *}$ and Xiaoqian $Q i^{4}$ \\ 1 School of Architecture, Tianjin University, Tianjin 300072, China; guanyi.yu@tju.edu.cn \\ 2 APEC Sustainable Energy Center, Tianjin University, Tianjin 300072, China \\ 3 College of Management and Economics, Tianjin University, Tianjin 300072, China \\ 4 School of Transportation Engineering, Dalian Maritime University, Dalian 116026, China; \\ Q_xiaoqian@163.com \\ * Correspondence: qianglin@tju.edu.cn; Tel./Fax: +86-022-27400847
}

check for

updates

Citation: Yu, G.; Lin, Q.; Qi, X. Government Incentive Contracts for Microgrid Users. Energies 2021, 14, 994. https://doi.org/10.3390/ en14040994

Received: 6 January 2021

Accepted: 11 February 2021

Published: 14 February 2021

Publisher's Note: MDPI stays neutral with regard to jurisdictional claims in published maps and institutional affiliations.

Copyright: (c) 2021 by the authors. Licensee MDPI, Basel, Switzerland. This article is an open access article distributed under the terms and conditions of the Creative Commons Attribution (CC BY) license (https:/ / creativecommons.org/licenses/by/ $4.0 /)$.

\begin{abstract}
Tariff subsidies are beneficial to the further development of the microgrid market. In response to the reduction of the power generation costs of microgrids, the energy storage subsidy for microgrids has become a key factor affecting their further development. Therefore, it is essential to explore and establish a government subsidy mechanism for the energy storage price of microgrids. In this paper, we consider the incentive compatibility constraints and participation constraints of both the government and the microgrid energy storage subsidy. The cases of hidden information and no hidden information are investigated. A microgrid energy storage subsidy model of the incentive compatibility constraint was established to analyze the efficiency of the government subsidy and the microgrid energy storage in the "self-generation + energy storage" mode. The results show that there is an adverse selection problem between the government and energy storage subsidies for microgrid users. In the case of no hidden information, the government can sign different contracts with microgrid users according to their different energy storage efficiency levels. In the case of hidden information, it is better for the government to design a menu of different incentive contracts for microgrid users with different energy storage efficiencies. This approach can ensure that microgrid users with low energy storage efficiency continue to participate in the microgrid construction. Microgrid users with high energy storage efficiency can, thus, better control their costs related to the self-generation, self-use, and surplus electricity transmitted to the grid as well as better select high-regulation carbon dioxide emission reductions and their capacity generation.
\end{abstract}

Keywords: government; microgrid users; incentive contracts; hidden information; subsidy

\section{Introduction}

Over recent years, China has entered a new round of the energy revolution, which is oriented toward diversified and clean energy. This revolution aims to improve the energy structure and promote a transformation of the energy strategy, featuring clean energy, smart grids, and microgrids. The rapid development of microgrids is changing the structures of electricity markets around the world [1,2]. Microgrids are assumed to be a key way to increase the share of renewable energy power (wind power, photovoltaic power generation, and biomass) $[3,4]$.

In reality, increasingly, enterprises apply for microgrid projects merely to obtain the associated high subsidies. From the perspective of a sustainable market economy development, such a long-term high subsidy policy increases the financial burden for the government and is not an optimal incentive plan [5]. More importantly, unreasonable subsidies favor specific enterprises, thus reducing the utility of incentive schemes. It is difficult for the government (or other relevant departments) to identify the true generation efficiency and energy storage efficiency of microgrids. The ensuing information asymmetry leads to a reduction of the incentive effect of government regulation policies. Therefore, the formulation of efficient incentive contract policies to promote the healthy and sustainable development of microgrid enterprises is an urgent requirement [6]. 
Microgrid operation can reduce greenhouse gas emissions, thus inducing additional environmental benefits [7]. Government incentive schemes generally aim to maximize both environmental and economic benefits, while microgrid users generally aim to maximize personal benefits [8]. Therefore, conflicts of interest and information asymmetry emerge between the government and microgrid users. This meets the basic assumptions of the principal-agent model.

Energy storage is a key factor of microgrid technology. It enables peak load shifting, which ensures a highly reliable power supply. During the 13th Five-Year Plan period, energy storage has been listed as one of the top 100 engineering projects, which is the first time that energy storage has been part of China's development plan. Since batteries for energy storage account for the largest proportion of microgrid investment, energy storage will benefit most from government subsidies, and energy storage also can add social value.

Adverse selection is often caused by information asymmetry within the principalagent relationship between the government and microgrid users. This paper considers incentive compatibility constraints and participation constraints of the government and the microgrid energy storage subsidy. In the cases of hidden information and complete lack of information, this paper establishes a microgrid energy storage subsidy model. This model incorporates an incentive compatibility constraint and analyzes the impact of energy storage efficiency. The optimal regulation toward carbon dioxide emission reduction, generating capacity on government subsidies, and social welfare, are analyzed. This provides a solid decision-making basis for both the government and microgrid users.

Compared with traditional fossil energy power, microgrids suffer from higher unit power generation costs, a lack of technical standards, and a suboptimal regulatory system. Therefore, the government often issues incentive regulations or provides high subsidies for enterprises or consumers to encourage the construction of microgrids [9]. A number of EU countries have introduced a green warrant price mechanism, which offers clear advantages toward reducing the risk of investors and promoting industrial technology progress. The government uses two types of incentive regulation policies for the renewable energy power generation industry: feed-in tariffs (FITs) and renewable portfolio standard (RPS). These two incentive regulation policies exert a support effect on the European renewable energy power generation industry [10-12].

With regard to government incentive regulation policies, Janzen et al. [13] and Pagliaro [14] studied wind power microgrids and presented a comparative analysis of industry regulation policies for 12 countries. They found that FITs were more conducive to reducing market uncertainty and ensuring investor benefits, thus forming a stable wind power development market. Khan et al. [15] compared and analyzed the incentive effects of the FIT and RPS for Denmark, Germany, and the United Kingdom from the perspectives of industrial sustainable development and employment opportunities. They found that the FIT was superior to RPS in this context.

Zhang et al. [16] compared the competition influence of German FITs and United Kingdom RPS on the wind power microgrid market. They found that, in practice, the German FIT was more conducive for the German microgrids (i.e., wind power market) to induce competition, which is contrary to the theoretical result. The reason is that the German wind power market is associated with more advantages in the construction of power transmission and the distribution network, thus reducing the networking costs of wind power. Palmquist et al. [17] conducted a questionnaire survey of 60 professional fund investment advisers in developed countries, such as European countries and the United States. Their empirical study identified FITs as the optimal incentive regulation policy that offers the greatest incentive effect in the development and application dimension of renewable energy technologies.

With regard to government incentives and subsidies for microgrids, Yu et al. [18] and Copiello et al. [19] suggested that microgrid power generation has positive externalities (e.g., resource conservation and environmental protection) and has positive social benefits. Therefore, the government must encourage and guide its use. Yu et al. and Copiello et al. 
also suggested that the incentive of microgrid power generation should be included in the energy incentive. An incentive should be formulated with policies related to microgrid power generation, where building energy conservation and environmental protection should be particularly considered. In addition, the supply and demand of the market should also be considered, and the investment desire, enthusiasm, and energy of the market should be leveraged through policy incentives.

This will jointly promote the construction of power generation microgrids. Azimian et al. [20] argued that economic incentives should be best applied for microgrid power generation, and that industry standards, barriers to entry, and laws and regulations should be established accordingly. This approach will achieve better incentives through tolerant entry and strict exit, driven by multiple policies. Lima suggested that energy-saving and environmentally friendly microgrid buildings are ideal to develop photovoltaic microgrid power generation. Policies and incentives should, therefore, be integrated into building design codes to promote the use of solar energy in buildings. Guttman [21] studied government incentive measures adopted by developed countries with good microgrid power generation and suggested that comprehensive economic policies should be adopted for comprehensive incentives.

Haber [22] studied the implementation effect of microgrid power generation tax policies among European countries. Davos suggested that the key point of developing microgrid power generation lies not in preferential taxation but in equipment subsidies, preferential feed-in tariffs, and the enactment of relevant laws and regulations with regard to industry standards and construction requirements. Odeh et al. [23] suggested that, although the current costs of photovoltaic power generation decreased with the progress of science and technology, compared with traditional power generation, the costs are still relatively high. Future development cannot be separated from the policy support of the government.

Pillot et al. [24] analyzed the solar energy policies of countries such as the United States, Canada, Germany, Spain, and France. They found that FITs, RPS, and government incentive measures were the most effective ways to promote the development of photovoltaic power generation. Consequently, these measures are widely implemented in many countries across the world. Luigi et al. [25] used cash flow, net present value, and the internal rate of return indicators to conduct an economic analysis on the photovoltaic power generation policies of European countries. The results showed that the political, legal, and economic systems of a country affect its policy effects on photovoltaic power generation.

Nong et al. [26] assessed wind power generation as an example, and reviewed a series of policies and measures to promote the development of renewable energy in China. They suggested that wind power concession operation offered a good reference value for the development of photovoltaic power generation. Coria et al. [27] compared the photovoltaic incentive policies of five countries that are representative for photovoltaic power generation (i.e., France, Germany, Japan, Spain, and the United States). They suggested that good policy design plays an important role in the promotion of the largescale layout of photovoltaic power.

Sahu [28] and Garcia-Alvarez et al. [29] found that government subsidies were an effective means to promote the development of photovoltaic power generation by analyzing the government support policies of leading countries in photovoltaic power generation. Zhai [30] calculated the required financial subsidies to enhance distributed photovoltaic power generation applications and highlighted the necessity for further financial support.

In the research method of incentive regulation, the principal-agent theory is the basic theory to describe and analyze incentive problems. Thomson et al. [31] first introduced the principal-agent theory to solve a company's conflict of interest. Ross [32] first analyzed the moral hazard problem in principal-agent theory, where the agent arbitrarily takes actions that affect the quality of the generated products. Hirsch et al. [33] analyzed adverse selection in principal-agent theory (where an enterprise will hide information in negotiations with 
the government to gain a benefit, even if its negotiating power is weak). The principalagent theory was extended to the government purchasing and regulation zone.

Zhu et al. [34] applied the principal-agent theory to the design of a mechanism to identify conflicts of interest between the government and economic sectors. At present, more and more scholars have applied the principal-agent theory to the research of government policy making $[35,36]$. Wang et al. [37] used the principal-agent theory to design subsidy policies to encourage enterprises to conserve energy and reduce their emissions. Wang et al. [38] and Liu applied a principal-agent model to study the incentive utility of governmental preference in public-private partnership (PPP) projects. Wang et al. [39] studied the incentive utility of tax policies by analyzing the post-event behaviors of both government and enterprises.

These summarized studies provide an important reference for the government's incentive regulation and incentive policies on microgrids. Many scholars have suggested that subsidies are conducive to the development of the renewable energy power industry. However, most available studies only considered the government's incentive policies for microgrids, while fewer studies considered the dominant factor of the government's energy storage subsidies or the hidden information between the government and microgrid users. Thus far, little research in China and internationally has addressed the government's contract incentive for microgrid users.

The present study proposes a government incentive contract method for microgrid users. First, we established a microgrid user energy storage subsidy model, incorporating energy storage efficiency, to analyze microgrid development in China. Second, the impact of energy storage efficiency on the optimal regulation of carbon dioxide emission reduction was analyzed. Optimal energy storage subsidies and user benefits were analyzed from the perspective of hidden information and no hidden information to investigate the effects of subsidy policies. Finally, policy recommendations for the government's formulation of microgrid incentive contracts are suggested as a possible solution to aid the Chinese government in promoting the further development of the microgrid industry.

The rest of the article is structured as follows. Section 2 introduces the applicability analysis of the model and describes the modeling process. In Section 3, we consider the model refinement analysis of hidden information and non-hidden information in the case of adverse selection. In Section 4, we conduct an empirical analysis of the models in the two scenarios and discuss the results. Then, the prediction accuracy of the model is tested. In Section 5, we summarize the conclusions and provide suggestions.

\section{Mathematical Framework}

\subsection{Principal-Agent Theory}

Principal-agent theory is the basic theory to describe and analyze incentive problems. The core problem of principal-agent theory is how to design an effective incentive and restraint mechanism to make the operator (agent) act in accordance with the requirements of maximizing the interests of the owner (principal) and reduce the agency cost. The theory and incentive structure of the principal and agent can solve the problem of benefit sharing and risk sharing. There are few studies on the development of microgrid based on the principal-agent theory, and they focus mainly on the formation of the principalagent relationship between a large power grid and shared users. In particular, due to the decentralization of microgrid users, large-scale organizations need to sign the same format contract with decentralized users through the contract agency to seek new cooperation and ultimately maximize the benefits, resource sharing, and organization scale.

\subsection{Method Description}

In this study, we used principal-agent theory to explore the incentive-compatible constraint relationship between government and microgrid users. Here, the principal cannot directly observe the behavior of the agent but can obtain specific variables. These variables are mainly generated by both the agent and external uncertainties. As a result, 
the principal has to design a mechanism in which the interests of the agent are as consistent as possible with the interests of the principal.

Consequently, the agent's subjective efforts fully (or relatively fully) meet the interests of the principal. This is the so-called "incentive constraint mechanism design", which is also known as a typical contract mechanism design. It can be planned according to the following three stages: (1) The principal creates an incentive contract for the agent. Here, the contract is a game plan, and under its rules, the agent sends corresponding signals that will eventually dominate the matching results. (2) The agent chooses whether to agree or disagree with the contract proposed by the principal. The agent only obtains the exogenous reserved utility if the agent does not accept the contract. (3) The agent accepting the mechanism plays games according to the relevant contents.

The essence of the self-generation + energy storage mode is that users own the microgrid system as well as both its operation rights and property rights. Part of the power generated by the microgrid is used by users, while surplus power is stored by a variety of energy storage equipment. The users can obtain power generation subsidies and energy storage subsidies for each watt and, gradually, the electricity price subsidies will be replaced by electricity storage subsidies.

For most users with a positive attitude toward distributed power generation, the most ideal mode is the self-generation + energy storage mode. In this mode, users can not only obtain a higher price for the electricity they generate, but they can also store the surplus electricity to meet irregular power requirements. However, many obstacles emerge in the actual operation process due to the information imbalance between microgrid practitioners and local grid company personnel. The hurdle of understanding professional knowledge makes it very difficult to understand the processing of microgrid electricity price policies and new government policies. This is also the reason for the change of the mode.

After choosing the self-generation + energy storage mode, users hope that they can completely generate electricity and consume it themselves. In the case of surplus, they can use energy storage equipment for storage to avoid resource waste. However, electric power companies want users to support themselves or produce electricity for the grid with a boost. From the perspective of local electric power companies, the analyses of the self-generation + energy storage mode show that their workload has increased compared with the past. The reasons can be found in calculating the capacity of regional power distribution and strengthening the management of power supply points. In the future developmental process, distributed electricity price subsidies will be widely used. For example, in the current photovoltaic subsidy policy, the self-generation + energy storage mode is a profit mode that can maximize benefits. In other words, this mode can maximize the expected income while ensuring bottom profits.

Based on the above model background and description, the principal-agent model is established. In this principal-agent model, the two sides of the game are the government and microgrid users. Here, microgrid users refers to the electric power users who have constructed the microgrid themselves and operate it in the self-generation + energy storage mode. They can also be called investors. The government is the principal, microgrid users are agents, and both sides are considered rational. The goal of the government is to maximize the social welfare utility, while microgrid users pursue the maximization of their own income under the requirements of the government entrustment contract. Energy storage benefits the most from government subsidies, and so, here, subsidy mainly refers to the subsidy for energy storage costs, which is referred to as an energy storage subsidy. The game and incentive subsidy process between the government and microgrid users mainly occurs during the early stage of a project; therefore, this section is mainly aimed at adverse selection.

Since the energy storage efficiency of microgrid users pertains to private information that is not accessible by the government, this information is hidden from the government. This implies that the government has to make the contract offer under the circumstance of information asymmetry. Such a situation involves information screening. The government 
must screen different information from microgrid users, for which the government has to pay a certain amount of information rent; however, to reduce this rent, the efficiency and rent extraction have to be balanced.

Under the conditions of hidden information, microgrid users display their behavioral signals or information signals to the government through the signal transmission principle under the signal theory; thus, their energy storage efficiency is disclosed. The meaning behind this display principle is the choice of the optimal contract under the constraint of asymmetric information. The government issues contracts according to each type of energy storage efficiency that the microgrid users may utilize. The microgrid users with different energy storage efficiencies can choose their favorable contracts according to different incentives. Consequently, the government needs to design an optimal incentive mechanism to induce microgrid users to make decisions according to the pursuit of the social welfare maximization by the government.

\subsection{Model Description}

\subsubsection{Model Hypothesis}

Hypothesis 1 (H1). The government, as both the principal and regulator, formulates a contract to assign certain energy storage subsidies to microgrid users. The microgrid user, as the agent, sets the minimum expected income of the microgrid project. If the contract formulated by the regulator fails to meet the minimum expected income of the microgrid user, the microgrid user will refuse to sign the contract. Microgrid projects are to be completed by microgrid users, regardless of changes in their scale.

Hypothesis 2 (H2). It can be assumed that the feed-in tariff is a fixed constant. The optimal energy storage subsidy contract is established based on data of the total cost of microgrid construction and the expected carbon dioxide emission reduction. The government needs to consider the participation constraint of microgrid users, i.e., their minimum expected income.

Hypothesis 3 (H3). The cost function of the microgrid is $C_{e}=\eta-k$, where $\eta$ represents the energy storage efficiency parameter of microgrid users, and $k$ represents the post-event effort level parameter of microgrid users [40]. Here, we only consider the problem of adverse selection, $k=0$.

Hypothesis 4 (H4). The power generation costs, $C_{e}$, of the microgrid are only related to the power generating capacity $\beta$, the carbon dioxide emission reduction $R$, and the system efficiency $\eta$. The power generation costs of the microgrid invested by microgrid users include the construction costs, which cover the raw material costs, project array costs, and costs to support power transmission and transformation. Emission reduction also includes carbon dioxide emissions from raw materials in the whole life cycle. The cost function $C_{e}(R(\eta), \beta(\eta), \eta)$ of microgrids is a strictly convex increasing function of the rated carbon dioxide emission reduction $R$, and a decreasing function of the energy storage efficiency $\eta[40]$.

$$
\frac{\partial C(R(\eta), \eta)}{\partial \eta} \leq 0 ; \frac{\partial^{2} C(R(\eta), \eta)}{\partial R \partial \eta} \leq 0 ; \frac{\partial^{3} C(R(\eta), \eta)}{\partial R^{2} \partial \eta} \leq 0 ; \frac{\partial^{3} C(R(\eta), \eta)}{\partial R \partial \eta^{2}} \geq 0
$$

Hypothesis 5 (H5). The energy storage efficiency of microgrid users is private information, which the government does not know [40]. The density function and the distribution function of microgrid users are $f(\cdot)$ and $F(\cdot)$, respectively, and the risk rate $\frac{1-F(\cdot)}{f(\cdot)}$ is non-increasing. The microgrid users are risk-neutral [40]: $\frac{d}{d \eta}\left(\frac{1-F(\eta)}{f(\eta)}\right) \leq 0 \quad \eta \in(0,1)$.

The process the government follows to formulate the optimal contract is a three-stage game with incomplete information: First, the overall investment of microgrid users is investigated and assessed. This includes the microgrid users' energy storage efficiency, power generation, and development potential. A contract is designed to cover the energy storage 
subsidy, generating capacity, and rated dioxide emission reduction, $C_{e}(R(\eta), \beta(\eta), \eta)$. This contract is a game plan. Relevant government departments monitor the power generation process of microgrid users and assess whether the carbon dioxide emission reduction reaches the standard stipulated in the contract. This ensures the smooth implementation of the contract as formulated by the government. Second, microgrid users can choose to either accept or reject the contract presented by the government. Finally, the microgrid users who have accepted the contract play games according to the provisions of the contract. They adjust both the power generation scale and production strategy according to the actual energy storage efficiency to maximize their income.

The government presents a contract menu, $C_{e}(R(\eta), \beta(\eta), \eta)$, of energy storage efficiency $\eta$ to microgrid users. Users then select the corresponding contract according to their actual energy storage efficiency level. Then, the government can learn about the real energy storage efficiency of the microgrid users according to their choices and determine the energy storage subsidy for these microgrid users based on their energy storage efficiency. Assuming that the energy storage efficiency of microgrid users, as observed by the government during the contract selection, is $\eta^{*}$, the energy storage subsidy, rated carbon dioxide emission reduction, and generating capacity selected by the microgrid users are expressed as $C_{e}\left(R\left(\eta^{*}\right), \beta\left(\eta^{*}\right), \eta\right)$.

\subsubsection{Decision-Making Model}

The government expects that microgrid construction financed by microgrid users can yield the maximum welfare utility for the whole society. The revenue of the government is the microgrid users' income, obtained by selling green electricity, which is further augmented by the environmental benefits induced by low-carbon emission reductions minus the government's energy storage subsidy [41], namely,

$$
E\left[\gamma \beta(\eta)+i R(\eta)-T_{e}(\eta)\right]
$$

where $T_{e}$ represents the energy storage subsidy from the government to microgrid users, $i$ represents the influence coefficient of carbon dioxide emission reduction per unit on total revenue, and $\gamma$ represents the influence coefficient of generating capacity per unit on the total revenue.

From the microgrid user perspective, their income originates from the energy storage subsidy from the government and the profit of selling surplus electricity to the state grid. Therefore, the final income is the microgrid users' income minus the costs of the microgrid. $V_{e}$ indicates the microgrid users' income, and the function is expressed as follows:

$$
V_{e}=T_{e}(\eta)+\gamma \beta(\eta)-C_{e}(R(\eta), \beta(\eta), \eta)
$$

\section{Model Analysis}

This chapter presents adverse selections in two scenarios: hidden information and no hidden information. The energy storage efficiency, $\eta \in(0,1)$, is assumed to be a continuous random variable.

\subsection{No Hidden Information}

In the case of no hidden information, the energy storage efficiency parameter is complete information. The government incentive compatibility constraint condition is not involved. Consequently, the maximization of the social welfare utility, under the participation constraint condition that meets users' minimum expected income, is the only factor to be considered, as expressed in the following model:

$$
\left\{\begin{array}{l}
\max E\left[\gamma \beta(\eta)+i R(\eta)-T_{e}(\eta)\right] \\
\text { subject to: } \\
V_{e}\left(T_{e}(\eta), R(\eta), \beta(\eta), \eta\right) \geq \mu_{c}
\end{array}\right.
$$


In Equation (4), the generating capacity and the rated carbon dioxide emission reduction should be as large as possible. The government energy storage subsidy should be as low as possible to maximize the social welfare utility, $\gamma \beta(\eta)+i R(\eta)-T_{e}(\eta)$. The high cost of microgrid development and high technical requirements obstruct the construction of microgrids for economic power users. Therefore, such economic power users will only participate in the microgrid if the minimum benefit they obtain from building microgrids exceeds their opportunity costs. The optimal energy storage subsidy is $T_{e}(\eta)=\mu_{c}+C_{e}(R(\eta), \beta(\eta), \eta)$. Incorporating this equation into Equation (4), we obtain the latest social welfare utility function:

$$
E(\eta)=\gamma \beta(\eta)+i R(\eta)-\mu_{c}-C_{e}(R(\eta), \beta(\eta), \eta)
$$

For the first partial derivatives of $R$ and $\beta$, when the utility of social welfare is at the maximum, the first partial derivative is 0 .

$$
\frac{\partial E(\eta)}{\partial R}=i-\frac{\partial C_{e}\left(R^{*}(\eta), \beta(\eta), \eta\right)}{\partial R}=0 \frac{\partial E(\eta)}{\partial \beta}=\gamma-\frac{\partial C_{e}\left(R^{*}(\eta), \beta(\eta), \eta\right)}{\partial \beta}=0
$$

In the case of no hidden information, the optimal regulation emission reduction $R^{*}(\eta)$ and generating capacity $\beta^{*}(\eta)$ are presented as follows:

$$
\frac{\partial C_{e}\left(R^{*}(\eta), \beta(\eta), \eta\right)}{\partial R}=i, \frac{\partial C_{e}\left(R(\eta), \beta^{*}(\eta), \eta\right)}{\partial \beta}=\gamma
$$

Then, the optimal regulation emission reduction $R^{*}(\eta)$ and generating capacity $\beta^{*}(\eta)$ are substituted into the model to obtain the optimal energy storage subsidy, namely,

$$
T_{e}^{*}(\eta)=\mu_{c}+C_{e}\left(R^{*}(\eta), \beta^{*}(\eta), \eta\right)
$$

In the case of no hidden information, the energy storage efficiency of microgrid users can be accurately calculated by the government. The government will not pay excessive energy storage subsidies, and microgrid users cannot seek economic rents. The government can easily meet the model conditions by designing a contract that meets the retention benefits of microgrid users. With the aid of such an incentive contract, the government establishes an effective cost compensation mechanism that incentivizes microgrid users to build microgrids, thereby achieving effective user gains as well as maximum social welfare. With this incentive, microgrid users need to reduce the costs of the microgrid if they want to maximize their own interests, thereby further maximizing the social welfare utility induced by microgrid power generation.

\subsection{Hidden Information}

In this scenario, microgrid users are rational economists whose goal is to maximize their own interests while satisfying the government's optimal contracts. Here, the energy storage efficiency is their personal information. Therefore, there is a certain risk is involved. A microgrid user with energy storage efficiency $\eta$ declares his energy storage efficiency as $\eta^{*}\left(\eta \neq \eta^{*}\right), \eta, \eta^{*} \in(0,1)$. This would result in higher energy storage subsidies, lower regulation carbon dioxide emission reductions, and lower generating capacity requirements. The profit function of microgrid users is

$$
V_{e}\left(\eta, \eta^{*}\right)=T_{e}\left(\eta^{*}\right)+\gamma \beta\left(\eta^{*}\right)-C_{e}\left(R\left(\eta^{*}\right), \beta\left(\eta^{*}\right), \eta\right)
$$

Incentive compatibility indicates that microgrid users select contracts that are suitable for their energy storage efficiency. According to the signal display principle, the government's optimal contract problem can be simplified as a standard contract problem with additional incentive compatibility constraints. An analysis of this type of mechanism design was proposed by Jean Jacques Laffont [42]. To encourage microgrid users to pro- 
vide truthful information and maximize social welfare, the government constructs the corresponding incentive compatibility constraint condition, as follows:

$$
V_{e}\left(T_{e}(\eta), R(\eta), \beta(\eta), \eta\right) \geq V_{e}\left(T_{e}\left(\eta^{*}\right), R\left(\eta^{*}\right), \beta\left(\eta^{*}\right), \eta\right)
$$

$V_{e}\left(T_{e}(\eta), R(\eta), \beta(\eta), \eta\right)$ represents the income of the microgrid user with energy storage efficiency $\eta$, which is truthfully disclosed to the public. $V_{e}\left(T_{e}\left(\eta^{*}\right), R\left(\eta^{*}\right), \beta\left(\eta^{*}\right), \eta\right)$ indicates that the energy storage efficiency of a microgrid user, disclosed to the public, is $\eta^{*}$. Since the high costs of microgrid development and high technical requirements impede economic power users building microgrids, they will only participate in the microgrid if the minimum benefit they obtain from building microgrids exceeds their opportunity costs, $\mu_{c}$. Therefore, the government should also respect the participation constraints of microgrid users when formulating contracts, to meet the minimum expected income of microgrid users. Therefore, the participation constraint is as follows:

$$
V_{e}\left(T_{e}(\eta), R(\eta), \beta(\eta), \eta\right) \geq \mu_{c}
$$

Since energy storage efficiency is private information, the government should first calculate the corresponding energy storage subsidy, generating capacity, and regulation carbon dioxide emission reduction for every possible energy storage efficiency of microgrid users. Then, the government has to consider how to maximize the social welfare utility in the contract. Microgrid users have an information advantage over the government. As the party with information advantage, microgrid users can use this advantage to obtain more income than they could obtain under symmetric information, and the value of the excess is called "information rent". As a result, the government has to design a contract that is not only motivational and feasible, but that can also help to pay as little information rent as possible. Therefore, the government energy storage subsidy is converted into a sum of the expected income, total costs, and information rent $\left(-\int_{0}^{\eta} \frac{\partial C_{e}(R(\eta), \beta(\eta), \eta)}{\partial \eta} d \eta\right)$ of microgrid users. The government energy storage subsidy function can thus be converted to

$$
T_{e}(\eta)=\mu_{c}+C_{e}(R(\eta), \beta(\eta), \eta)-\int_{0}^{\eta} \frac{\partial C_{e}(R(\eta), \beta(\eta), \eta)}{\partial \eta} d \eta
$$

Equation (10) ensures that microgrid users can obtain the maximum profit when revealing their real energy storage efficiency. When $V_{e}$ is maximum, the first partial derivative is 0 , the second derivative is less than or equal to 0 , as $\frac{\partial V_{e}\left(\eta, \eta^{*}\right)}{\partial \eta^{*}} \mid \eta^{*}=\eta=0$, $\frac{\partial^{2} V_{e}\left(\eta, \eta^{*}\right)}{\partial \eta^{* 2}} \mid \eta^{*}=\eta \leq 0$, and we further draw

$$
\frac{d T_{e}(\eta)}{d \eta}-\frac{\partial C(R(\eta), \beta(\eta), \eta)}{\partial R} \frac{d R(\eta)}{d \eta}=0
$$

We can then find the derivative of Equation (13) with respect to $\eta$ :

$$
\frac{d^{2} T_{e}(\eta)}{d \eta^{2}}=R\left(\frac{d R(\eta)}{d \eta}\right)^{2}+\frac{\partial^{2} C(R(\eta), \beta(\eta), \eta)}{\partial R \partial \eta} \frac{d R(\eta)}{d \eta}+\frac{\partial C(R(\eta), \beta(\eta), \eta)}{\partial R} \frac{d^{2} R(\eta)}{d \eta^{2}}
$$

We can find the second derivative of $V_{e}$ with respect to $\eta^{*}$ as follows:

$$
\frac{d^{2} T_{e}(\eta)}{d \eta^{2}}-\frac{\partial^{2} C(R(\eta), \beta(\eta), \eta)}{\partial R^{2}}\left(\frac{d R(\eta)}{d \eta}\right)^{2}-\frac{\partial C(R(\eta), \beta(\eta), \eta)}{\partial R} \frac{d^{2} R(\eta)}{d \eta^{2}} \leq 0
$$

Combined with Equations (14) and (15), we concluded that

$$
\frac{\partial^{2} C(R(\eta), \beta(\eta), \eta)}{\partial R \partial \eta} \frac{d R(\eta)}{d \eta} \leq 0
$$


From the combined hypothesis, $\frac{\partial^{2} C(R(\eta), \beta(\eta), \eta)}{\partial R \partial \eta}<0$, we concluded that $\frac{d R(\eta)}{d \eta} \geq 0$.

When microgrid users show real efficiency, the profit function of the microgrid users is as specified in Equation (3). The total derivative of $\eta$ for Equation (3) can be determined as follows:

$$
\frac{d V_{e}\left(T_{e}(\eta), R(\eta), \beta(\eta), \eta\right)}{d \eta}=\frac{d T_{e}(\eta)}{d \eta}-\frac{\partial C(R(\eta), \beta(\eta), \eta)}{\partial R} \frac{d R(\eta)}{d \eta}-\frac{\partial C(R(\eta), \beta(\eta), \eta)}{\partial \eta}
$$

Substituting Equation (13) into Equation (17), we obtain

$$
\frac{d V_{e}\left(T_{e}(\eta), R(\eta), \beta(\eta), \eta\right)}{d \eta}=-\frac{\partial C(R(\eta), \beta(\eta), \eta)}{\partial \eta} \geq 0
$$

This indicates that $V_{e}\left(T_{e}(\eta), R(\eta), \beta(\eta), \eta\right)$ is an increasing function of $\eta$; the participation constraint can be expressed as follows:

$$
V_{e}(0)=T_{e}(0)-C_{e}(R(0), \beta(0), 0) \geq \mu_{c}
$$

When the government can implement the optimal cost compensation regulation for microgrid users,

$$
T_{e}(0)-C_{e}(R(0), \beta(0), 0)=\mu_{c}
$$

By substituting Equation (12) into Equation (2), the government welfare utility function is obtained as follows:

$$
E\left[\gamma \beta(\eta)+i R(\eta)-\mu_{c}-C_{e}(R(\eta), \beta(\eta), \eta)+\int_{0}^{\eta} \frac{\partial C_{e}(R(\eta), \beta(\eta), \eta)}{\partial \eta} d \eta\right]
$$

The objective function is further simplified as

$$
\left\{\begin{array}{l}
\max \int_{0}^{1}\left[\gamma \beta(\eta)+i R(\eta)-C_{e}(R(\eta), \beta(\eta), \eta)+\frac{1-F(\eta)}{f(\eta)} \cdot \frac{\partial C_{e}(R(\eta), \beta(\eta), \eta)}{\partial \eta}\right] \\
\text { subject to: } \\
\frac{d R(\eta)}{d \eta} \geq 0, \forall \eta \in \Omega
\end{array}\right.
$$

By using the partial derivative of $R$ and $C_{e}$ from the above formula, the optimal regulation carbon dioxide emission reduction and the energy storage subsidy can be obtained as follows:

$$
\left\{\begin{array}{c}
\frac{\partial C\left(R^{* *}(\eta), \beta(\eta), \eta\right)}{\partial R}=i+\frac{1-F(\eta)}{f(\eta)} \cdot \frac{\partial^{2} C(R(\eta), \beta(\eta), \eta)}{\partial R \eta \eta} \\
T_{e}^{* *}(\eta)=\mu_{c}+C\left(R^{* *}(\eta), \beta(\eta), \eta\right)-\int_{0}^{\eta} \frac{\partial C\left(R^{* *}(\eta), \beta(\eta), \eta\right)}{\partial \eta} d \eta
\end{array}\right.
$$

Therefore, in the case of hidden information, the principal-agent model can be simplified as

$$
\left\{\begin{array}{l}
\max \int_{0}^{1}\left[\gamma \beta(\eta)+i R(\eta)-C_{e}(R(\eta), \beta(\eta), \eta)+\frac{1-F(\eta)}{f(\eta)} \cdot \frac{\partial C_{e}(R(\eta), \beta(\eta), \eta)}{\partial \eta}\right] \\
\text { subject to : } \\
\frac{d R(\eta)}{d \eta} \geq 0, \forall \eta \in \Omega \\
V_{e}\left(T_{e}(\eta), R(\eta), \beta(\eta), \eta\right) \geq V_{e}\left(T_{e}\left(\eta^{*}\right), R\left(\eta^{*}\right), \beta\left(\eta^{*}\right), \eta\right) \\
V_{e}\left(T_{e}(\eta), R(\eta), \beta(\eta), \eta\right) \geq \mu_{c}
\end{array}\right.
$$

In the case of hidden information, the principal-agent model has two maximization problems of inequality constraints. With regard to the first inequality, from the perspective of microgrid users, they are more willing to keep information about their energy storage efficiency secret. They determine the optimal course of action according to their own ability to maximize their utility and extract rental profits from the government. However, from the perspective of the government, to maximize the social welfare utility via cooperating with microgrid users, 
the government must consider whether to provide rents or incentives to mitigate the negative impacts of microgrid users' private information on the social welfare utility.

The government, therefore, should design a contract menu that provides different energy storage subsidies for microgrid users with different energy storage efficiency levels. The government needs to allow microgrid users to choose whether to disclose their private information. In this case, microgrid users with high energy storage efficiency, who can better control costs under the self-generation + energy storage mode, will choose a higher regulation carbon dioxide emission reduction and the generation of capacity.

\section{Results and Discussion}

The 7.203 MW microgrid project in Qumalai, Yushu, Qinghai, China, is a power supply project that was configured with a $5 \mathrm{MWh}$ lithium battery, a $20 \mathrm{MWh}$ energy storage system, and a $7 \mathrm{MW}$ photovoltaic power generation system. The installed capacity of the photovoltaic power generation system was 7.203 MW, which was the rated power of the photovoltaic power station and was taken according to the actual data of the project. The rated maximum storage capacities of the lithium battery energy storage system and lead-acid battery energy storage system were 5 and 20 MWh, respectively. Lithium battery energy storage has the advantages of fast charging and discharging times, high efficiency, and long service life. It is relatively advanced, but its price is high.

Lead-acid batteries have relatively slow charge and discharge times, and are low in efficiency and short in life, but they are inexpensive. The project used two kinds of energy storage batteries at the same time; the purpose was to give full play to the biggest advantages of batteries under the most economic conditions. Lithium batteries provide a stable voltage and frequency for the grid daily, and lead-acid batteries supply power for the load under more extreme conditions. The combination of the two can support a largescale optical storage power station and ensure high reliability of the system. The actual operational data of this project was used to verify the validity of the model. Assuming that the energy storage efficiency, $\eta \in(0,1)$, of microgrid users is a continuous random variable, the following density function and distribution function can be obtained:

$$
f(\eta)=\left\{\begin{array}{cc}
1 \quad 0<\eta<1 \\
0 \text { others }
\end{array}, F(\eta)=\left\{\begin{array}{cc}
0 & \eta \leq 0 \\
\eta \quad 0<\eta<1 \\
1 \quad \eta \geq 1
\end{array}\right.\right.
$$

In reference to the model analysis method of Couture and Gagnon, in the microgrid project, the social benefit coefficient is $\delta=0.2$ (which emerges from the generating capacity per unit), the social benefit coefficient is $i=5$ (which emerges from the carbon dioxide per unit), and the expected profit of the cost function can be assumed to be $C_{e}(R(\eta), \beta(\eta), \eta)=$ $5 R^{2}\left(2+e^{\frac{1}{\beta}}\right)(2-\eta)$.

Then, according to Equation (24), the model is simplified as

$$
\left\{\begin{array}{l}
\max E\left[5 R(\eta)-T_{e}(\eta)+0.2 \beta(\eta)\right] \\
\text { subject to: } \\
P(\eta)-5 R^{2}\left(2+e^{\frac{1}{\beta}}\right)(2-\eta)+0.2 \beta(\eta) \geq P\left(\eta^{*}\right)-5 R^{2}\left(2+e^{\frac{1}{\beta}}\right)\left(2-\eta^{*}\right)+0.2 \beta(\eta) \\
P(\eta)-5 R^{2}\left(2+e^{\frac{1}{\beta}}\right)(2-\eta)+0.2 \beta(\eta) \geq 0
\end{array}\right.
$$

According to the model analysis presented in the previous section, both the optimal regulation of the carbon dioxide emission reduction $R^{*}(\eta)=\frac{1}{6-4 \eta}$, in the case of no hidden information, and the optimal regulation of the carbon dioxide emission reduction $R^{* *}(\eta)=\frac{1}{14-8 \eta}$, in the case of hidden information, can be obtained. These are both based on the assumption that, in the case of the energy storage efficiency $\eta \in(0,1)$, the social benefit coefficient is $\delta=0.2$, the social benefit coefficient is $i=5$ (which emerges from the carbon dioxide per unit), and the expected income is $\mu_{c}=0$. Using MATLAB, the 
influence of energy storage efficiency on the optimal regulation of the carbon dioxide emission reduction, the optimal energy storage subsidy, and user benefits are depicted in Figures 1-3.

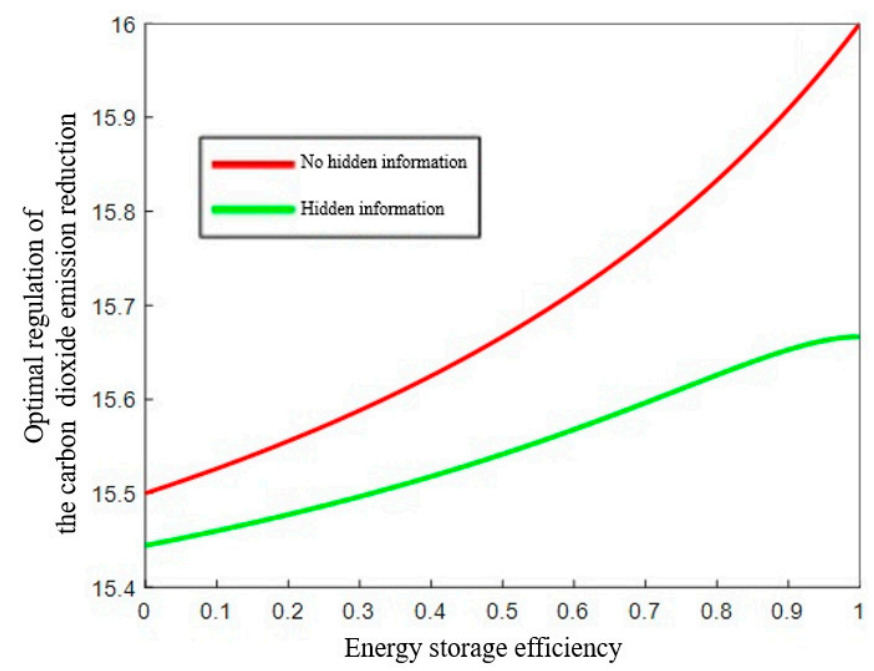

Figure 1. The influence of the energy storage efficiency on the optimal regulation of the carbon dioxide emission reduction.

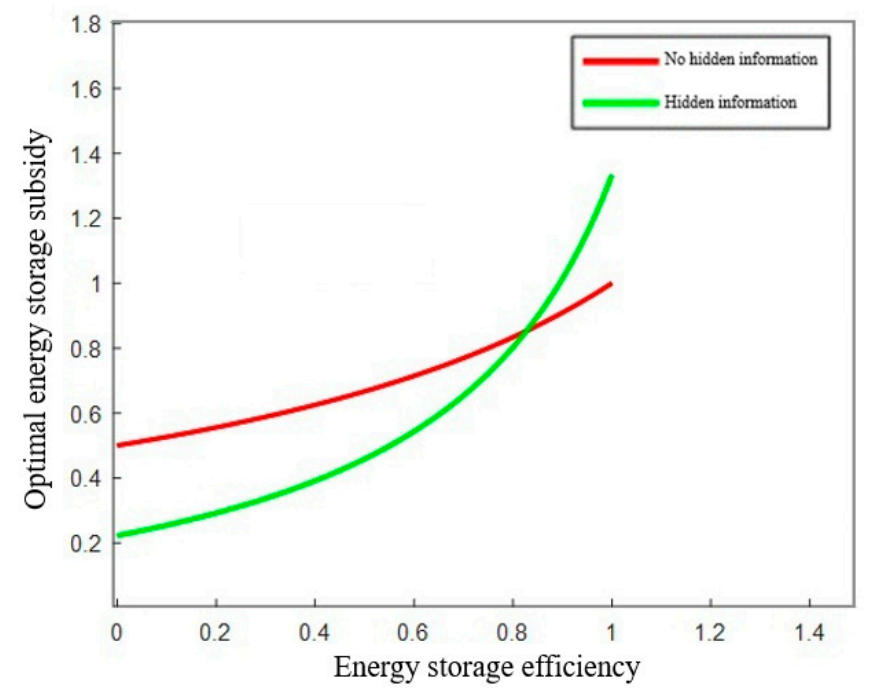

Figure 2. The influence of the energy storage efficiency on the optimal energy storage subsidy.

As shown in Figure 1, in case of no hidden information, the government knows exactly the energy storage efficiency of the microgrid users. With further improvements of the energy storage efficiency, the optimal regulation of the carbon dioxide emission reduction also increases. In the case of hidden information, the government does not know the energy storage efficiency of microgrid users, and the optimal regulation of the carbon dioxide emission reduction increases with the improvement of energy storage efficiency. The difference is that the optimal regulation of the carbon dioxide emission reduction under no hidden information exceeds that under hidden information. The reason for this phenomenon is that the higher the energy storage efficiency of microgrid users, the higher the efficiency of energy conservation and emission reduction will be, and accordingly, a higher specification of carbon dioxide emission reduction will be formulated by the government.

As shown in Figure 2, in the case of no hidden information, the government's optimal energy storage subsidy level increases with the increasing energy storage efficiency of microgrid users. In the case of hidden information, the government's optimal energy 
storage subsidy level increases with the increasing energy storage efficiency. An intersection point exists between both lines. To the left of the intersection point, where the energy storage efficiency is low, the government's optimal energy storage subsidy level under no hidden information is higher than under hidden information. To the right of the intersection point, where the energy storage efficiency is high, the government's optimal subsidy level under hidden information is higher than under no hidden information.

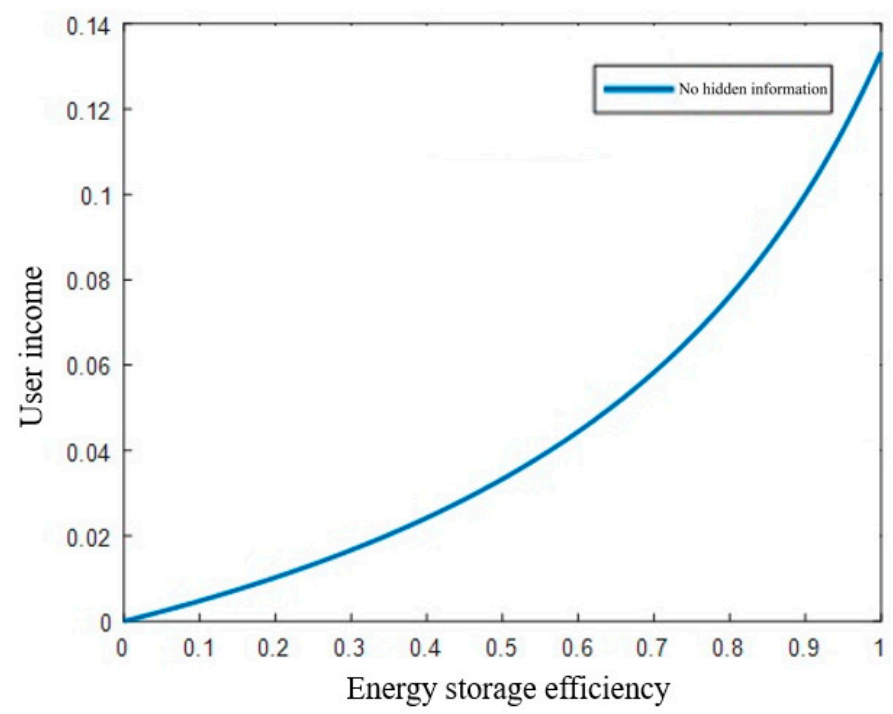

Figure 3. The influence of the energy storage efficiency on user income.

The reason for this phenomenon is that, if the users' energy storage efficiency is low and the government learns about it, the government will adopt a cost-plus inefficient incentive contract for microgrid users. This guarantees that, at the beginning of the industrial development, even microgrids with low energy storage efficiency and high costs still attract the continuous participation of economic power users to further invest in construction. When the users' energy storage efficiency is high, the government will adopt a fixed price efficient incentive contract for microgrid users to avoid rent-seeking behavior by the user and also to decrease government financial expenditure. Investing more support funds for economic power users will further promote their enthusiasm to build microgrids and transmit surplus electricity to the grid, thus achieving both energy conservation and emission reductions.

As shown in Figure 3, with the continuous improvement of the energy storage efficiency of microgrid users, their income increases. The higher the user's energy storage efficiency, the more the user can control the construction and operation costs in the process of microgrid power generation. This improves the income of the microgrid user.

\section{Conclusions}

This study developed a principal-agent model between the government and microgrid users by applying the contract theory to analyze the optimal incentive contract. The government is the principal, and the microgrid user is the agent. The key contradiction points of both sides are that their interests are not consistent and that hidden information may exist. The principal created a contract menu to design the optimal contract while also ensuring the maximum benefits. We present the following conclusions:

For the government, the energy storage efficiency level of microgrid users is not a clear value, but rather a series of government estimates of the capacity of microgrid users. According to the government's estimations of the energy storage efficiency of microgrid users, the optimal energy storage subsidy that the government should provide can be determined. The optimal regulation of the carbon dioxide emission reduction, the optimal energy storage subsidy, and the user income in the contract menu are all positively related 
to the energy storage efficiency. They are also related to the existence of hidden information. The contract menu is a collection of contracts that both the government and microgrid users are willing to accept. The government can sign different contracts with microgrid users based on differences in their energy storage efficiency levels.

In the case of no hidden information, the government knows the energy storage efficiency of the microgrid users and will therefore avoid paying excessive energy storage subsidies. Instead, the government only needs to design an incentive contract that meets the retention benefits of microgrid users. In the case of hidden information, the government does not know the energy storage efficiency of microgrid users, which causes adverse selection problems. Since microgrid users hold the information advantage over the government, microgrid users can use this advantage to obtain more income than they could obtain without hidden information. This excess value is called "information rent".

Correspondingly, the government needs to pay a certain information rent. The government needs to assess whether rents or incentives should be provided. Therefore, it is better for the government to design a menu of different incentive contracts for microgrid users with different energy storage efficiencies and allow microgrid users to make their own choices. In this way, increases in government spending as a result of user rent-seeking behavior can be avoided. This approach can also ensure that microgrid users with low energy storage efficiency continue to participate in the microgrid construction. Simultaneously, microgrid users with high energy storage efficiency, who can thus better control the costs in the self-generation, self-use, and surplus electricity transmitted to the grid, will select high-regulation carbon dioxide emission reductions and capacity generation.

Author Contributions: G.Y. proposed the concept of this research and completed the manuscript. Q.L. analyzed the empirical data. X.Q. gave suggestions. All authors have read and agreed to the published version of the manuscript.

Funding: This research was funded by the National Social Science Foundation of China (No. 19CGL006).

Acknowledgments: This research was supported by the National Social Science Foundation of China (No. 19CGL006).

Conflicts of Interest: The authors declare no conflict of interest.

\section{Abbreviations}

$\eta \quad$ energy storage efficiency parameter of microgrid users

$\eta^{*} \quad$ energy storage efficiency of microgrid users

$k \quad$ post-event effort level parameter of microgrid users

$\beta \quad$ power generating capacity

$i \quad$ influence coefficient of carbon dioxide emission reduction per unit on total revenue

$\gamma \quad$ influence coefficient of generating capacity per unit on total revenue

$\delta \quad$ social benefit coefficient (which emerges from the generating capacity per unit)

$R \quad$ carbon dioxide emission reduction

$C_{e} \quad$ power generation costs

$T_{e} \quad$ energy storage subsidy from the government to microgrid users

$V_{e} \quad$ microgrid users' income

$\mu_{c} \quad$ opportunity cost

$f(\cdot) \quad$ density function

$F(\cdot) \quad$ distribution function

$\beta(\eta) \quad$ generating capacity

$R(\eta) \quad$ rated carbon dioxide emission reduction

$R^{*}(\eta) \quad$ regulation emission reduction

$\beta^{*}(\eta) \quad$ generating capacity

$W^{*}(x) \quad$ optimal regulation of the

carbon dioxide emission reduction (in the case of no hidden information)

$W^{* *}(x) \quad$ optimal regulation of the carbon dioxide emission reduction (in the case of hidden information) 


\section{References}

1. Recalde, A.A.; Alvarez-Alvarado, M.S. Design optimization for reliability improvement in microgrids with wind-tidalphotovoltaic generation. Electr. Power Syst. Res. 2020, 188, 106540. [CrossRef]

2. Holari, Y.T.; Taher, S.A.; Mehrasa, M. Distributed energy storage system-based nonlinear control strategy for hybrid microgrid power management included wind/PV units in grid-connected operation. Int. Trans. Electr. Energy Syst. 2019, 30 , e12237.

3. Hashmi, S.A.; Ali, C.F.; Zafar, S. Internet of things and cloud computing-based energy management system for demand side management in smart grid. Int. J. Energy Res. 2021, 45, 1007-1022. [CrossRef]

4. Tu, H.; Du, Y.; Yu, H.; Dubey, A.; Lukic, S.; Karsai, G. Resilient Information Architecture Platform for the Smart Grid: A Novel Open-Source Platform for Microgrid Control. IEEE Trans. Ind. Electron. 2020, 67, 9393-9404. [CrossRef]

5. Fan, J.L.; Xu, M.; Yang, L.; Zhang, X. Benefit evaluation of investment in CCS retrofitting of coal-fired power plants and PV power plants in China based on real options. Renew. Sustain. Energy Rev. 2019, 115, 109350. [CrossRef]

6. Allan, G.; Eromenko, I.; Gilmartin, M.; Kockar, I.; McGregor, P. The economics of distributed energy generation: A literature review. Renew. Sustain. Energy Rev. 2015, 42, 543-556. [CrossRef]

7. Aghajani, G.R.; Shayanfar, H.A.; Shayeghi, H. Presenting a multi-objective generation scheduling model for pricing demand response rate in micro-grid energy management. Energy Conv. Manag. 2015, 106, 308-321. [CrossRef]

8. Aboelsood, Z.; Hossam, A.; Gabbar, A.E. Optimal planning of combined heat and power systems within microgrids. Energy 2015, 93, 235-244.

9. Burtt, D.; Dargusch, P. The cost-effectiveness of household photovoltaic systems in reducing greenhouse gas emissions in Australia: Linking subsidies with emission reductions. Appl. Energy 2015, 148, 439-448. [CrossRef]

10. Colombo, L.; Labrecciosa, P. Dynamic oligopoly pricing with reference-price effects. Eur. J. Oper. Res. 2021, 288, 1006-1016. [CrossRef]

11. Yu, S.; Zheng, Y.; Li, L. A comprehensive evaluation of the development and utilization of China's regional renewable energy. Energy Policy 2019, 127, 73-86. [CrossRef]

12. Angelus, A. Distributed Renewable Power Generation and Implications for Capacity Investment and Electricity Prices. Prod. Oper. Manag. 2020, 6, 3172207.

13. Janzen, R.; Davis, M.; Kumar, A. Greenhouse gas emission abatement potential and associated costs of integrating renewable and low carbon energy technologies into the Canadian oil sands. J. Clean Prod. 2020, 272, 122820. [CrossRef]

14. Pagliaro, M. Renewable energy in Russia: A critical perspective. Energy Sci. Eng. 2020, 10, 1-8. [CrossRef]

15. Khan, M.I.; Khan, I.A.; Chang, Y.C. An overview of global renewable energy trends and current practices in Pakistan-A perspective of policy implications. J. Renew. Sustain. Energy 2020, 12, 56301. [CrossRef]

16. Zhang, Y.Z.; Zhao, X.G.; Ren, L.Z.; Zuo, Y. The development of the renewable energy power industry under feed-in tariff and renewable portfolio standard: A case study of China's wind power industry. J. Clean Prod. 2017, 168, 1262-1276. [CrossRef]

17. Palmquist, S.; Bask, M. Market dynamics of buyout acquisitions in the renewable energy and cleantech sectors: An event study approach. Renew. Sustain. Energy Rev. 2016, 64, 271-278. [CrossRef]

18. Yu, S.; Tan, Q.; Evans, M.; Kyle, P.; Vu, L.; Patel, P.L. Improving building energy efficiency in India: State-level analysis of building energy efficiency policies. Energy Policy 2017, 110, 331-341. [CrossRef]

19. Copiello, S. Economic implications of the energy issue: Evidence for a positive non-linear relation between embodied energy and construction cost. Energy Build. 2016, 123, 59-70. [CrossRef]

20. Azimian, M.; Amir, V.; Javadi, S. Economic and Environmental Policy Analysis for Emission-Neutral Multi-Carrier Microgrid Deployment. Appl. Energy 2020, 277, 115609. [CrossRef]

21. Guttman, J.M. On the Evolutionary Stability of Preferences for Reciprocity. Eur. J. Polit. Econ. 2015, 16, 31-50. [CrossRef]

22. Haber, W. Landscape ecology as a bridge from ecosystems to human ecology. Ecol. Res. 2004, 19, 546-552. [CrossRef]

23. Odeh, R.P.; Watts, D. Impacts of wind and solar spatial diversification on its market value: A case study of the Chilean electricity market. Renew. Sustain. Energy Rev. 2019, 111, 442-461. [CrossRef]

24. Pillot, B.; Muselli, M.; Poggi, P.; Dias, J.B. Historical trends in global energy policy and renewable power system issues in Sub-Saharan Africa: The case of solar PV. Energy Policy 2019, 127, 113-124. [CrossRef]

25. Luigi, D.; Enrico, T. Economic analysis of different supporting policies for the production of electrical energy by solar photovoltaics in western European Union countries. Energy Policy 2012, 38, 3297-3308.

26. Nong, D.; Wang, C.; Al-Amin, A.Q. A critical review of energy resources, policies and scientific studies towards a cleaner and more sustainable economy in Vietnam. Renew. Sustain. Energy Rev. 2020, 134, 110-117. [CrossRef]

27. Coria, G.; Penizzotto, F.; Pringles, R. Economic analysis of photovoltaic projects: The Argentinian renewable generation policy for residential sectors. Renew. Energy 2019, 133, 1167-1177. [CrossRef]

28. Sahu, B.K. A study on global solar PV energy developments and policies with special focus on the top ten solar PV power producing countries. Renew. Sustain. Energy Rev. 2015, 43, 621-634. [CrossRef]

29. Garcia-Alvarez, M.T.; Cabeza-Garcia, L.; Soares, I. Assessment of energy policies to promote photovoltaic generation in the European Union. Energy 2018, 151, 864-874. [CrossRef]

30. Zhai, P. Analyzing solar energy policies using a three-tier model: A case study of photovoltaics adoption in Arizona, United States. Renew. Energy 2013, 57, 317-322. [CrossRef] 
31. Thomson, J. Governance costs and defence intelligence provision in the UK: A case-study in microeconomic theory. Intell. Natl. Secur. 2016, 31, 844-857. [CrossRef]

32. Ross, S.A. The economic theory of agency: The principal's problem. Am. Econ. Rev. 1973, 63, 134-139.

33. Hirsch, A.V.; Shotts, K.W. Policy-Development Monopolies: Adverse Consequences and Institutional Responses. J. Polit. 2018, 80, 1339-1354. [CrossRef]

34. Zhu, D.R.; Wang, R.; Duan, J.D.; Cheng, W.J. Comprehensive weight method based on game theory for identify critical transmission lines in power system. Int. J. Electr. Power Energy Syst. 2021, 124, 106362. [CrossRef]

35. Rommel, J.; Verhoest, K. Exploring effects of coordination on the autonomy of regulators: Energy regulators in Belgium. Int. Rev. Adm. Sci. 2014, 80, 298-317. [CrossRef]

36. Hu, D.; Wang, Y.D.; Yang, X. Trading Your Diversification Strategy for a Green One: How Do Firms in Emerging Economies Get on the Green Train? Organ Environ. 2019, 32, 391-415. [CrossRef]

37. Wang, Y.Y.; Fan, R.J.; Shen, L.; Miller, W. Recycling decisions of low-carbon e-commerce closed-loop supply chain under government subsidy mechanism and altruistic preference. J. Clean Prod. 2020, 259, 120883. [CrossRef]

38. Wang, Y.L.; Liu, J.C. Evaluation of the excess revenue sharing ratio in PPP projects using principal-agent models. Int. J. Proj. Manag. 2015, 33, 1317-1324. [CrossRef]

39. Wang, H.; Huang, W.Y. On the Study of a Single-Period Principal-Agent Model with Taxation. Math. Probl. Eng. 2020, 2020, 5401591. [CrossRef]

40. Laffont, J.J.; Tirole, J. A Theory of Incentives in Procurement and Regulation; The MIT Press: Cambridge, MA, USA, $1993 ;$ pp. 54-55.

41. Chen, W.D.; Fan, W.L.; Zang, W.J.; Yu, G.Y. Optimal cost-reimbursement rules combining carbon emission reduction targets with power conversion efficiency for microgrid firms. Fresenius Environ. Bull. 2017, 26, 3182-3190.

42. Laffont, J.J.; Martimort, D. The Theory of Incentives: The Principal-Agent Model; Princeton University Press: Princeton, NJ, USA, 2001; pp. 23-25. 